\title{
KEBUTUHAN SDM UJI TAK RUSAK UNTUK INSPEKSI PRE- SERVICE PADA PEMBANGUNAN PLTN PERTAMA DI INDONESIA
}

\author{
Sri Nitiswati \\ Pusat Teknologi Reaktor dan Keselamatan Nuklir - BATAN \\ Puspiptek, Gedung No. 80, Setu - Tangerang Selatan 15314
}

\begin{abstract}
ABSTRAK
KEBUTUHAN SDM UJI TAK RUSAK UNTUK INSPEKSI PRE-SERVICE PADA PEMBANGUNAN PLTN PERTAMA DI INDONESIA. Peraturan Presiden Nomor 5 tahun 2006 tentang "kebijakan energi nasional" menyebutkan bahwa Indonesia telah memasukkan opsi nuklir ke dalam energi mix nasional untuk mendukung kebutuhan energi di masa mendatang. Artinya pembangunan pembangkit listrik tenaga nuklir (PLTN) sudah menjadi salah satu pilihan bangsa Indonesia untuk memenuhi kebutuhan energi. Pembangunan PLTN tidak bisa terlepas dari kebutuhan sumber daya manusia (SDM) termasuk SDM uji tak rusak yang penting pada tahap pabrikasi komponen PLTN yaitu untuk melakukan pemeriksaan/inspeksi komponen hasil fabrikasi atau yang biasa disebut dengan inspeksi pre-service. Data pemeriksaan komponen hasil dari fabrikasi digunakan sebagai informasi data awal kondisi komponen PLTN sebelum dioperasikan. Makalah ini membahas kebutuhan SDM uji tak rusak untuk inspeksi pre-service pada pembangunan PLTN pertama di Indonesia khususnya untuk memeriksa/inspeksi hasil pabrikasi komponen. Metode dengan cara melakukan identifikasi komponen-komponen yang berada di dalam sistem primer reaktor PWR (Pressurized Water Reactor), identifikasi bagian dari komponen yang harus diperiksa, metode uji tak rusak dan tekniknya serta kebutuhan SDM nya. Tujuannya adalah diperolehnya kebutuhan SDM uji tak rusak untuk melakukan inspeksi pre-service pada pembangunan PLTN I di Indonesia. Dari studi yang dilakukan disimpulkan bahwa SDM dengan kompetensi uji tak rusak metode visual, volumetrik dan permukaan diperlukan untuk inspeksi pre-service komponen-komponen hasil fabrikasi. Kebutuhan SDM berdasarkan volume pekerjaan adalah untuk kompetensi UTR visual level 1: 10 orang, level $2: 8$ orang, level 3 : 5 orang. Kompetensi UTR volumetrik level 1: 22 orang, level $2: 13$ orang, level $3: 9$ orang. Kompetensi UTR permukaan level 1: 8 orang, level $2: 7$ orang, level $3: 4$ orang.
\end{abstract}

Kata kunci: sumber daya manuasia, uji tak rusak, pembangkit listrik tenaga nuklir

\section{ABSTRACT}

NON-DESTRUCTIVE TESTING PERSONNEL NEEDS FOR PRE-SERVICE INSPECTION OF THE FIRST NUCLEAR POWER PLANT CONSTRUCTION IN INDONESIA. President act number 5, 2006 on "national energy" has declared that indonesia has decided nuclear option into national mix energy to support future energy needs. it means that construction of nuclear power plant (npp) has become insight to fulfill needs of indonesian energy. the need of non-destructive testing personnel in fabrication stage of npp components is very important to examine/inspect fabricated components, called pre-service inspection. the data of examined components of fabrication result will be used as base line data of initial component condition. this paper discusses on the need of non-destructive testing personnel to conduct pre-service inspection for construction the first nuclear power plant in indonesia especially personnel to examine/inspect components of fabrication result. the method covered identification of the pwr components in reactor primary system, identification parts of component should be examined/inspected, non-destructive testing method and technique, and need of its personnel. aim of this study is to obtain non-destructive testing personnel needs to conduct pre-service inspection for the first nuclear power plant construction in indonesia. the need of personnel based on task volume is visual level 1:10 person, level $2: 8$ person, level $3: 5$ person. . volumetric competent for level 1: 22 person, level $2: 13$ person, level $3: 9$ person. surface competent level 1: 8 person, level $2: 7$ person, level $3: 4$ person.

Keywords: personnel, non destructive testing, nuclear power plant 


\section{PENDAHULUAN}

Peraturan Presiden Nomor 5 tahun 2006 tentang "Kebijakan Energi Nasional" meyebutkan bahwa Indonesia telah memasukkan opsi nuklir ke dalam energi mix nasional untuk mendukung kebutuhan energi di masa mendatang. ${ }^{1}$ Hal ini berarti cepat atau lambat Indonesia akan membangun pembangkit listrik tenaga nuklir (PLTN). Komponen PLTN harus mempunyai kehandalan yang tinggi, sehingga mampu beroperasi dengan aman dan selamat sampai umur desain dicapai atau bahkan sampai melebihi umur desainnya. Hal ini dapat dipenuhi sepanjang operator PLTN melaksanakan manajemen umur PLTN yang dimulai sejak tahap pabrikasi komponen PLTN, yaitu dengan terpenuhinya persyaratan pabrikasi komponen PLTN. Misalnya pabrikasi bejana tekan, pembangkit uap, sistem perpipaan dan komponen-komponen lainnya dipersyaratkan tidak boleh ada diskontinuitas material misalnya retak dan porositas baik pada bagian sambungan yang dilas maupun bahan induknya diluar kriteria penerimaan standar uji tak rusak. Oleh karena itu kontraktor yang melakukan pembangunan memerlukan sumber daya manusia uji tak rusak (SDM-UTR) untuk memeriksa atau inspeksi kondisi komponen hasil pabrikasi sebelum komponen tersebut diserahkan ke pemilik PLTN atau sebelum komponen digunakan/dioperasikan. Makalah ini membahas perkiraan kebutuhan kontraktor dalam menyediakan SDM-UTR untuk melakukan inspeksi pre-service dalam pembangunan PLTN pertama tipe PWR (pressurizer water reactor), khususnya SDM-UTR untuk memeriksa/inspeksi komponen hasil fabrikasi. Lingkupnya dibatasi hanya untuk komponenkomponen yang berada didalam sistem primer reaktor yang mengacu pada AP-1000 desain Westinghouse. Metodenya dengan cara melakukan identifikasi komponen-komponen yang berada di dalam sistem primer reaktor PWR, kemudian dilanjutkan identifikasi bagian dari komponen yang harus diperiksa/diinspeksi, metode uji tak rusak dan tekniknya serta memperkirakan kebutuhan SDM nya. Tujuannya adalah diperolehnya kebutuhan SDM uji tak rusak untuk melakukan inspeksi preservice pada pembangunan PLTN I di Indonesia. Diharapkan dengan melakukan studi ini dapat diperkirakan kebutuhan SDM uji tak rusak dalam kegiatan pembangunan PLTN I di Indonesia.

\section{Komponen Sistem Primer Reaktor PWR Yang Diperiksa}

Komponen-komponen yang berada di dalam sistem primer reaktor terdiri dari ${ }^{2}$ : bejana tekan reaktor (reactor vessel), pembangkit uap (steam generator), pressurizer (tabung penekan), pompa dan pipa pendingin reaktor yang mempunyai 2 loop.
Masing-masing loop terdiri dari 1 sisi panas (hot leg) dan 2 sisi dingin (cold legs) ditunjukkan pada Gambar 1. Seluruh komponen tersebut diperiksa kecuali pompa yang telah melalui pemeriksaan khusus dalam fabrikasinya.

\section{Bejana Tekan Reaktor}

Bejana tekan reaktor terbuat dari bahan paduan feritik atau baja karbon rendah yang dilapisi (liner) dengan stainless steel dan dibentuk dengan teknologi tempa melingkar besar (large ring forgings) sehingga menghasilkan struktur bejana. Struktur bejana disusun dari beberapa bagian (shell) yang dikonstruksi dengan cara disambung dengan las melingkar[3]. Bagian yang dilas ini adalah bagian yang rentan, karena ketika proses pengelasan dapat terjadi cacat las misalnya retak dan porositas, sehingga perlu dilakukan pemeriksaan atau inspeksi terhadap hasil pabrikasi. Pada bejana tekan terdapat flange, nosel-nosel keluaran/masukan, rumah batang kendali (control rod housing) serta nosel instrumentasi yang terbuat dari stainless steel yang melekat pada dinding bejana tekan dengan cara dilas. Las-lasan flange dan nosel merupakan "dissimilar metal weld". Bagian nosel ini termasuk bagian yang rentan terjadi cacat. Bagian dari bejana tekan yang harus diperiksa adalah seluruh sambungan las-lasan antar shell dan sambungan laslasan antara flange dan nozel-nozel dengan shell bejana tekan. $^{[3-5]}$

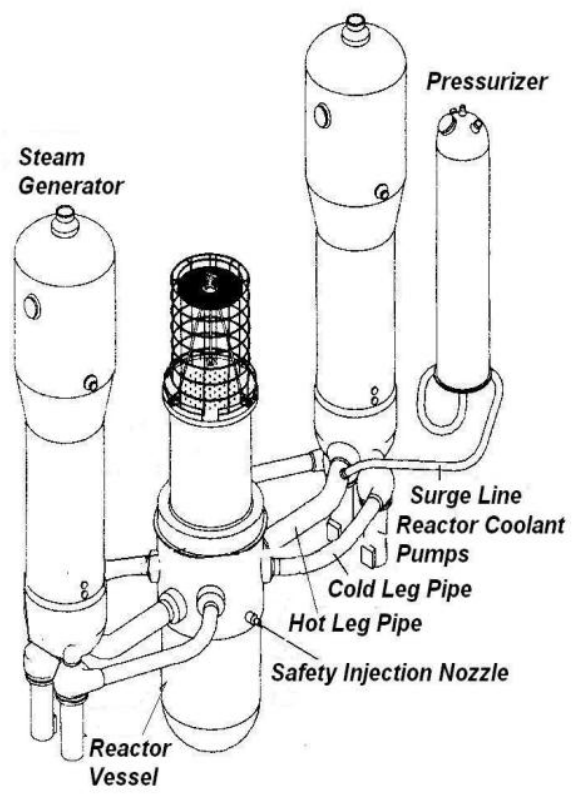

Gambar 1. Komponen Sistem Primer PWRAP1000 (Desain Westinghouse-USA) ${ }^{[2]}$

\section{Pembangkit Uap}

Ada 2 tipe Pembangkit Uap, yaitu recirculating atau yang dikenal dengan tipe shell 
and $U$-tubes, dan once-through. Kedua tipe tersebut bagian luarnya dibungkus dengan shell yang berbentuk bejana. Bejana disusun dari beberapa bagian shell, dimana antara shell yang satu dengan shell yang lainnya dikonstruksi dengan cara disambung dengan dilas melingkar. Untuk satu buah pembangkit uap (desain terkini) mempunyai jumlah tabung (tube) mencapai antara 10.000 sampai dengan 12.500 tabung atau sekitar 20.000 sampai dengan 25.000 lubang tabung ${ }^{[2]}$. Proses pembuatan tabung secara ekstrusi sehingga sangat memungkinkan ketebalan setiap tabung tidak merata dan tidak sama. Oleh karena itu setiap tabung hasil ekstrusi harus diperiksa untuk diketahui ketebalan awalnya sebelum pembangkit uap dioperasikan. Tabung bagian $U$-bend (tipe recirculating) termasuk bagian yang harus diperiksa karena pada bagian $U$ bend sangat rentan terhadap retakan sebagai akibat dari proses fabrikasi yang menghasilkan tegangan sisa lokal yang lebih tinggi dari pada tabung bagian lurus. Pada arah berlawanan dari $U$-bend terdapat lubang masukan dan keluaran yang disebut dengan "cold leg" dan "hot leg" yang harus diperiksa. ${ }^{[4-5]}$

\section{Pressurizer (Tabung Penekan)}

Pressurizer terbuat dari pelat baja karbon rendah yang dibentuk dan dilas secara melingkar sehingga menghasilkan struktur bejana. Struktur bejana disusun dari beberapa bagian shell yang dikonstruksi dengan cara disambung dengan las. Pada pressurizer terdapat banyak nosel-nosel, antara lain nosel surge line, spray line dan nosel penetrasi instrumentasi yang terbuat dari austenitic stainless steel yang dikonstruksi dengan cara dilas pada dinding bejana pressurizer. Bagian dari pressurizer yang harus diperiksa adalah seluruh sambungan las-lasan yang terdapat pada dinding bejana pressurizer dan sambungan las-lasan antara nozel-nozel dengan dinding bejana pressurizer. ${ }^{[2,5]}$

\section{Pipa Pendingin Reaktor}

Pipa pendingin reaktor tersusun dari pipa pendingin utama (hot leg dan cold leg) dan noselnosel yang umumnya terbuat dari bahan stainless steel. Pada sistem perpipaannya terdapat elbow dan cabang pipa. Nosel dan pipa-pipa bercabang dikonstruksi dengan cara dilas pada bagian dinding komponen lainnya yang berhubungan seperti pressurizer, pembangkit uap dan bejana tekan sehingga pada bagian yang dilas tersebut merupakan "dissimilar metal welds". Bagian dari pipa pendingin reaktor yang harus diperiksa adalah seluruh sambungan las-lasan antara pipa pendingin utama dengan nosel, dengan cabang-cabang pipa serta sambungan las-lasan antara pipa pendingin utama dengan dinding bejana pressurizer, dinding bejana pembangkit uap, serta dinding bejana $\operatorname{tekan}^{[2,5]}$.

\section{Metode Uji Tak Rusak dan Standar yang Digunakan}

Metode dan standar yang digunakan untuk inspeksi pre-service adalah sama dengan metode dan standar yang digunakan untuk inspeksi inservice, yaitu ASME Section XI. ${ }^{[3-4]}$

Secara umum ada 3 metode uji tak rusak yang digunakan untuk inspeksi pre-service, yaitu metode visual, metode permukaan, dan metode volumetrik. Termasuk dalam metode visual ada 2 (dua) yaitu visual langsung dengan menggunakan kaca pembesar dan visual dengan menggunakan telescope, boroscope, dan endoscope. Termasuk dalam metode permukaan adalah cairan penetran dan partikel magnetik. Termasuk dalam metode volumetrik adalah ultrasonik, arus eddy (eddy current), dan radiografi.

Tabel 1. Inspeksi Pre-service Bejana Tekan Reaktor ${ }^{[5]}$

\begin{tabular}{|c|c|c|}
\hline NO. & BAGIAN DIPERIKSA & METODE \\
\hline 1. & $\begin{array}{l}\text { Las-lasan melingkar pada } \\
\text { shell }\end{array}$ & Volumetrik \\
\hline 2. & $\begin{array}{l}\text { Las-lasan melingkar pada } \\
\text { head atas dan bawah }\end{array}$ & Volumetrik \\
\hline 3. & $\begin{array}{l}\text { Las-lasan shell dengan } \\
\text { flange }\end{array}$ & Volumetrik \\
\hline 4. & $\begin{array}{l}\text { Las-lasan head dengan } \\
\text { flange }\end{array}$ & $\begin{array}{l}\text { Volumetrik } \\
\text { dan } \\
\text { Permukaan }\end{array}$ \\
\hline 5. & $\begin{array}{l}\text { Las-lasan nosel dengan } \\
\text { shell }\end{array}$ & Volumetrik \\
\hline 6. & $\begin{array}{l}\text { Las-lasan nosel dengan } \\
\text { safe end butt }\end{array}$ & $\begin{array}{l}\text { Volumetrik } \\
\text { dan } \\
\text { Permukaan }\end{array}$ \\
\hline 7. & $\begin{array}{l}\text { Closure studs dan } \\
\text { kumparan flange }\end{array}$ & Volumetrik \\
\hline 8. & Closure head nuts & Visual \\
\hline 9. & Bolts, studs dan nuts & Visual \\
\hline 10. & $\begin{array}{l}\text { Las-lasan rumah penggerak } \\
\text { batang kendali }\end{array}$ & $\begin{array}{c}\text { Volumetrik } \\
\text { atau } \\
\text { Permukaan }\end{array}$ \\
\hline
\end{tabular}

Masing-masing metode dan teknik mempunyai kelebihan, kekurangan dan penggunaan yang berbeda tergantung pada tujuan dan obyek yang diperiksa. Oleh karena itu dalam memeriksa komponen PLTN sering digunakan lebih dari 1 metode dan teknik uji tak rusak secara bersamaan. Misal teknik visual mempunyai keterbatasan hanya bisa untuk melihat secara visual kondisi permukaan suatu komponen. Namun untuk melihat lebih detail lagi misalnya retak permukaan atau sub. permukaan digunakan cairan penetrant dan ultrasonik..$^{5-6}$ Metode yang digunakan untuk inspeksi pre-service komponen-komponen sistem primer reaktor PWR ditunjukkan pada Tabel 1 sampai dengan Tabel 4 . Khusus untuk inspeksi pre-service bejana tekan 
selalu dimulai dengan metode visual dan setelah inspeksi pre-service selesai dilakukan dilanjutkan dengan uji kebocoran dan uji tekanan bejana tekana. ${ }^{[3,5]}$

\section{Tabel 2. Inspeksi Pre-service Pembangkit Uap ${ }^{[5]}$}

\begin{tabular}{|c|c|c|}
\hline NO. & BAGIAN DIPERIKSA & METODE \\
\hline 1. & $\begin{array}{l}\text { Las-lasan melingkar pada } \\
\text { head }\end{array}$ & Volumetrik \\
\hline 2. & $\begin{array}{l}\text { Las-lasan tubesheet dengan } \\
\text { head }\end{array}$ & Volumetrik \\
\hline 3. & $\begin{array}{l}\text { Las-lasan nosel dengan } \\
\text { bejana }\end{array}$ & Volumetrik \\
\hline 4. & $\begin{array}{l}\text { Las-lasan nosel dengan } \\
\text { safe end butt }\end{array}$ & $\begin{array}{l}\text { Volumetrik } \\
\text { dan } \\
\text { Permukaan }\end{array}$ \\
\hline 5 . & Bolts, studs & $\begin{array}{l}\text { Visual dan } \\
\text { Volumetrik }\end{array}$ \\
\hline 6. & $\begin{array}{l}\text { Permukaan flange dan nuts } \\
\text { Tabung lurus dan } U \text {-bend }\end{array}$ & $\begin{array}{c}\text { Visual } \\
\text { Volumetrik }\end{array}$ \\
\hline
\end{tabular}

Tabel 3. Inspection Pre-service Pressurizer ${ }^{[5]}$

\begin{tabular}{|c|c|c|}
\hline NO. & BAGIAN DIPERIKSA & METODE \\
\hline 1. & $\begin{array}{l}\text { Las-lasan melingkar shell } \\
\text { dengan head }\end{array}$ & Volumetrik \\
\hline 2. & $\begin{array}{l}\text { Las-lasan melingkar pada } \\
\text { head }\end{array}$ & Volumetrik \\
\hline 3. & $\begin{array}{l}\text { Las-lasan nosel dengan } \\
\text { bejana }\end{array}$ & Volumetrik \\
\hline 4. & $\begin{array}{l}\text { Las-lasan nosel dengan } \\
\text { safe end butt }\end{array}$ & $\begin{array}{l}\text { Volumetrik } \\
\text { dan }\end{array}$ \\
\hline 5. & Bolts dan studs & $\begin{array}{l}\text { Permukaan } \\
\text { Visual dan } \\
\text { Volumetrik }\end{array}$ \\
\hline 6. & Permukaan flange dan nuts & Visual \\
\hline
\end{tabular}

Peralatan yang digunakan untuk inspeksi pre-service seperti peralatan visual, ultrasonik dan eddy current bersifat fully automatic atau robotik sehingga pelaksanaan inspeksinya bisa dilakukan dengan lebih cepat dari pada menggunakan peralatan manual atau non fully autmatic atau non robotik.

Tabel 4. Inspeksi Pre-service Pipa Pendingin Reaktor $^{[5]}$

\begin{tabular}{clcc}
\hline NO. & \multicolumn{2}{c}{ BAGIAN DIPERIKSA } & METODE \\
\hline 1. & $\begin{array}{l}\text { Las-lasan melingkar pada } \\
\text { pipa utama }\end{array}$ & $\begin{array}{c}\text { Volumetrik } \\
\text { dan } \\
\text { permukaan }\end{array}$ \\
2. & $\begin{array}{l}\text { Las-lasan sambungana pipa } \\
\text { cabang }\end{array}$ & $\begin{array}{c}\text { Volumetrik } \\
\text { dan } \\
\text { Permukaan }\end{array}$ \\
3. & Bolts, studs dan nuts & Visual \\
\hline
\end{tabular}

Sri Nitiswati $(88-93)$

\section{Sumber Daya Manusia Uji Tak Rusak (SDM-UTR)}

SDM-UTR yang akan melakukan inspeksi pre-service harus mempunyai kompotensi yang sesuai dengan metode dan teknik UTR yang akan digunakan serta mempunyai kualifikasi tertentu yang dapat diklasifikasikan menjadi 3 (tiga) level, yaitu Level 1, Level 2, dan Level 3.

SDM-UTR dengan kualifikasi level 1 mempunyai tugas: menyiapkan dan melakukan setup peralatan yang akan digunakan, melakukan inspeksi, merekam dan mengklasifikasikan hasil inspeksi sesuai dengan kriteria yang telah ditetapkan sebelumnya serta melaporkan hasil inspeksi ${ }^{[6]}$.

SDM-UTR dengan kualifikasi level 2 mempunyai tugas: melakukan verifikasi kesiapan peralatan UTR yang akan digunakan, menyiapkan/ menterjemahkan Code, standar, dan prosedur pemeriksaan ke dalam suatu instruksi yang praktis, mengawasi pelaksanaan inspeksi dan semua tugas level 1, melakukan interpretasi dan evaluasi hasil inspeksi sesuai code, standar, membimbing level 1 , serta mengolah dan melaporkan hasil inspeksi. ${ }^{[7]}$

SDM-UTR dengan kualifikasi level 3 mempunyai tugas: bertanggungjawab penuh terhadap peralatan dan SDM-UTR, menetapkan dan mengesahkan metode, teknik dan prosedur yang akan digunakan, melakukan interpretasi code, standar dan prosedur, melakukan interpretasi dan evaluasi ulang hasil inspeksi berdasarkan code dan standar serta mengawasi tugas level 1 dan level 2. ${ }^{[7]}$

Dalam melakukan inpeksi pre-service, untuk satu tim inspeksi terdiri dari SDM-UTR level 1, level 2 dan level 3 sesuai dengan kompetensinya. Jumlah SDM-UTR level 2 dan level 3 biasanya lebih sedikit atau maksimum sama dengan jumlah SDM-UTR level 1.

\section{HASIL DAN PEMBAHASAN}

Durasi untuk melakukan inspeksi pre-service komponen-komponen yang berada didalam sistem primer reaktor berbeda-beda tergantung pada volume pekerjaan atau komponen yang diinspeksi. Jika reaktor yang akan dibangun adalah PWR tipe AP1000 (desain Westinghouse-USA). Spesifikasi sebagai berikut: ${ }^{[2]}$

Bejana tekan: tinggi $(12 \mathrm{~m})$, diameter dalam (3.988 mm) dan tebal dinding $(203 \mathrm{~mm})$. Bejana tekan desain terkini Westinghouse dibuat dengan sistem modular artinya tidak ada lasan vertikal dan terdiri dari 3 (tiga) modul atau shell ${ }^{3}$, dilas dengan penetrasi penuh (full penetration) melingkar. Berarti keliling lasan melingkar yang harus diperiksa termasuk head atas dan head bawah sekitar $106 \mathrm{~m}$. Total panjang lasan yang harus diperiksa $212 \mathrm{~m}$ dengan asumsi tambahan $100 \%$ untuk lasan nosel, flange, bolts, studs, nuts, lasan rumah penggerak 
batang kendali dan lasan komponen lainnya yang melekat pada bejana tekan. Inspeksi pre-service bejana tekan akan diselesaikan dalam waktu maksimum 10 hari kerja dan 8 jam per harinya (tidak termasuk perbaikan dan seting peralatan). Berarti panjang lasan yang harus diperiksa perhari minimum sekitar $22 \mathrm{~m}$. Apabila SDM-UTR khususnya level 1 volumetrik dapat melaksanakan pemeriksaan panjang lasan sekitar 10 m/orang/hari ${ }^{[8]}$, maka diperlukan SDM-UTR volumetrik level 1 sekitar 3 orang. SDM-UTR volumetrik level 2 yang bertugas untuk memeriksa hasil pekerjaan level 1 sekitar 2 orang dan level 3 diperlukan 1 orang. Sejenis dengan SDM-UTR volumetrik untuk memeriksa dengan visual dengan obyek dan volume pekerjaannya sama dengan volumetrik diperlukan masing-masing 3 orang level 1, 2 orang level 2 dan 1 orang level 3. Sedangkan untuk metode permukaan dimana obyek dan volume pekerjaannya jauh lebih sedikit yaitu sekitar sepertiga dari volume pekerjaan dengan volumetrik atau dengan visual, sehingga diperlukan SDM yang lebih sedikit yaitu 1 orang masing-masing untuk level 1, level 2 dan level 3.

Pembangkit uap tipe shell dan $U$-tube vertikal (resirculating): jumlah pembangkit uap ada 2 buah, masing-masing bundle tabung terdiri dari 10.025 tabung. Berarti untuk 2 pembangkit uap jumlah tabungnya ada 20.050 buah. Inspeksi preservice pembangkit uap akan diselesaikan dalam waktu maksimum 25 hari kerja dan 8 jam per harinya (tidak termasuk perbaikan dan seting peralatan). Berarti jumlah tabung yang harus diperiksa perhari minimum ada 802 tabung. Apabila SDM-UTR khususnya level 1 volumetrik dapat melaksanakan pemeriksaan tabung sekitar 75 tabung/orang/hari[9], maka diperlukan SDM-UTR volumetrik level 1 sekitar 11 orang, level 2 sekitar 6 orang dan level 3 sekitar 4 orang. Sedangkan SDMUTR untuk memeriksa secara visual dan permukaan dimana obyek dan volume pekerjaannya lebih sedikit dibandingkan dengan metode volumetrik, perkiraan diperlukan 3 orang untuk level 1, 2 orang untuk level 2 dan 2 orang level 3 untuk metode visual dan 2 orang level 1, 2 orang level 2 dan 1 orang level 3 untuk metode permukaan.

Pressurizer: diameternya 2,28 $\mathrm{m}$ dan tinggi $16,0 \mathrm{~m}$. Pressurizer terdiri dari 4 shell dilas full penetration melingkar. Berdasarkan data dapat diperkirakan volume pekerjaan untuk memeriksa pressurizer kira-kira setengah dari volume pekerjaan untuk memeriksa bejana tekan, ${ }^{2}$ karena pressurizer hanya merupakan sebuah bejana/tabung penekan dimana dibagian dalamnya tidak ada tabung-tabung ataupun batang kendali. Jika inspeksi pre-service pressurizer akan diselesaikan dalam waktu maksimum 10 hari kerja dan 8 jam per harinya (tidak termasuk perbaikan dan seting peralatan), maka diperlukan SDM-UTR volumetrik level 1 sekitar 5 orang. SDM-UTR volumetrik level 2 yang bertugas untuk memeriksa hasil pekerjaan level 1 sekitar 3 orang dan level 3 diperlukan 2 orang. Sejenis dengan SDM-UTR volumetrik untuk memeriksa dengan visual dan permukaan dengan obyek dan volume pekerjaannya lebih sedikit dibandingkan dengan metode volumetrik, diperlukan masing-masing 2 orang untuk level 1, 2 orang untuk level 2 dan 1 orang level 3.

Pipa pendingin reaktor: diameter dalam pipa sisi panas $790 \mathrm{~mm}$ dan diameter dalam pipa sisi dingin $560 \mathrm{~mm}$. Total panjang pipa sekitar $120 \mathrm{~m}$. Berdasarkan data ${ }^{2}$ dapat diperkirakan volume pekerjaan untuk memeriksa pipa primer reaktor, sehingga diperkirakan diperlukan SDM-UTR volumetrik dan permukaan masing-masing untuk level 1 sekitar 3 orang, level 2 sekitar 2 orang dan level 3 diperlukan 1 orang. Sejenis dengan SDMUTR volumetrik dan permukaan untuk memeriksa dengan visual dengan obyek dan volume pekerjaannya lebih sedikit dibandingkan dengan metode volumetrik dan permukaan, diperlukan masing-masing 2 orang untuk level 1, 2 orang level 2 dan 1 orang level 3.

SDM-UTR yang dibutuhkan ditabulasikan pada Tabel 5.

Tabel 5. SDM-UTR Dibutuhkan

\begin{tabular}{|c|c|c|c|c|}
\hline \multirow[t]{2}{*}{ NO. } & \multirow[t]{2}{*}{ KOMPONEN } & \multicolumn{3}{|c|}{ METODE } \\
\hline & & $\mathrm{I}$ & II & III \\
\hline \multirow[t]{4}{*}{1.} & Bejana tekan & & & \\
\hline & - $\quad$ Level 1 & 3 & 3 & 2 \\
\hline & - $\quad$ Level 2 & 2 & 2 & 1 \\
\hline & - $\quad$ Level 3 & 1 & 1 & 1 \\
\hline \multirow[t]{4}{*}{2.} & Pembangkit uap & & & \\
\hline & - $\quad$ Level 1 & 3 & 11 & 2 \\
\hline & - $\quad$ Level 2 & 2 & 6 & 2 \\
\hline & - Level 3 & 2 & 4 & 1 \\
\hline \multirow[t]{4}{*}{3.} & Pressurizer & & & \\
\hline & - $\quad$ Level 1 & 2 & 5 & 2 \\
\hline & - $\quad$ Level 2 & 2 & 3 & 2 \\
\hline & - $\quad$ Level 3 & 1 & 2 & 1 \\
\hline \multirow[t]{5}{*}{4.} & Pipa pendingin & & & \\
\hline & - Level 1 & 2 & 3 & 3 \\
\hline & - $\quad$ Level 2 & 2 & 2 & 2 \\
\hline & - $\quad$ Level 3 & 1 & 1 & 1 \\
\hline & JUMLAH & 23 & 43 & 20 \\
\hline
\end{tabular}

Keterangan:

I : Metode visual

II : Metode volumetrik

III : Metode permukaan 


\section{KESIMPULAN}

Kebutuhan sumber daya manusia uji tak rusak untuk melakukan inspeksi pre-service yang harus disediakan oleh kontraktor dalam rangka pembangunan PLTN I, adalah sebagai berikut : kompetensi yang diperlukan adalah dalam bidang UTR visual, volumetrik, dan permukaan. Kualifikasi SDM mencakup dari level 1, level 2, dan level 3 . Secara ringkas dapat disimpulkan kebutuhan SDMUTR untuk kompetensi UTR visual level 1: 10 orang, level 2: 8 orang, level 3: 5 orang. Kompetensi UTR volumetrik level 1: 22 orang, level 2: 13 orang, level 3: 9 orang. Kompetensi UTR permukaan level 1: 8 orang, level 2: 7 orang, level 3: 4 orang. Perkiraan kebutuhan SDM-UTR ini masih relevan apabila dibandingkan dengan SDM-UTR yang dibutuhkan ketika pembangunan PLTN Kori Unit 3 di Korea yang membutuhkan SDM-UTR untuk kompetensi UTR visual level 1 sekitar : 14 orang, level 2: 10 orang, level 3: 7 orang. Kompetensi UTR volumetrik level 1: sekitar 30 orang, level 2: 20 orang, level 3: 13 orang. Kompetensi UTR permukaan level 1: sekitar 15 orang, level 2: 10 orang dan level 3: 6 orang $^{[10]}$. Kebutuhan SDMUTR ketika pembangunan PLTN Kori Unit 3 di Korea lebih banyak dari kebutuhan SDM-UTR pada pembangunan PLTN pertama di Indonesia. Hal ini disebabkan oleh peralatan UTR masih dioperasikan secara manual dan belum fully automatic (robotic).

\section{DAFTAR PUSTAKA}

1. Peraturan Presiden No. 5 "Tentang Kebijakan Energi Nasional", 2006

2. International Atomic Energy Agency, "Status of Advanced Light water Reactor Design", IAEATECDOC-1391, May, 2004
3. International Atomic Energy Agency, "Integrity of Reactor Pressure Vessel in Nuclear Power Plants: Assessment on Irradiation Embrittlement Effects in Reactor Pressure Vessel Steels", IAEA-TECDOC-XXX (26 November 2007)

4. ASME Boiler And Pressue Essel Code, "Rules for Construction of Nuclear Facility Components", Section III, Division 1Subsection NB, Class 1 Components, Edition 2007.

5. ASME Boiler And Pressure Vessel Code, "Rules for In-Service Inspection of Nuclear Power Plant Components", Section XI, Edition 2007

6. International Atomic Energy Agency, "InService Inspection of Nuclear Power Plant", safety Practices, Safety Series No.50-P-2, Vienna, 1991

7. International Standard Organisation, "Non Destructive Testing-Personal Qualification and certification", ISO, 9712:1999(E)

8. Kim, K.M., "Specialist for the Nuclear PreService and In-Service Inspection", Komunikasi Pribadi, Oktober, 2006

9. NITISWATI, S., "Power Reactor-On The Job Training on In-Service Inspection of Kori Unit 3 Steam Generator", Korea, Agustus, 2000

10. YIM, C.J., "KAITEC-Specialist for the Nuclear Pre-Service and In-Service Inspection", Komunikasi Pribadi, Agustus, 2000 